ICGRG - Int. Comm. on General Relativity and Gravitation, A. Held (Sec.), Inst. of Theoretical Physics, Silderstrasse 5, CH-3012 Bern [+41 (31) - / 6544 05]

ICO - Int. Comm. for Optics, J.S. Dainty (Sec.-Gen.), Blackett Lab., Imperial College, London SW7 2BZ, UK [+44 (71) 58951 11/ 58475 96]

ICRM - Int. Committee for Radionuclei Metrology, D.D. Hoppes (Sec.),

US Dept. of Commerce, Nat. Inst. of Standards and Technology, Gaithersburg, MA 20899, USA

ICRU - Int. Comm. on Radiation Units \& Measurements, Inc., W.R. Ney (Chief Op. Off.), 7910 Woodmont Ave., Suite 800, Bethesda, MA 20814-3095, USA [+1 (301) $6572652 / 90787$ 68]

ICSTI - Int. Council for Scientific \& Technical Information, M. Orfus (Exec. Sec.), 51, blvd. de Montmorency, F-75016 Paris [+33 (1) $45256592 / 42881466]$

ICSU - Int. Council of Scientific Unions, J. Marton-Lefevre (Exec. Sec.), 51, blvd. de Montmorency, F-75016 Paris [+33 (1) $45250329 / 42889431]$

ICTP - Int. Centre for Theo. Physics, A. Salam (Dir.), Strada Costiera, 11, POB 586, 1-34100 Trieste [+39 (40) $22401 / 224163]$

IEC - Int. Electrotechnical Comm., A.E. Raeburn (Gen.-Sec.), 3, rue de Varembé, $\mathrm{CH}-1211$ Geneva 20 [+41 (22) $7340150 /$ - ]

IIASA - Int. Inst. for Applied Systems Analysis, P.E. de Jánosi (Dir.), A-2361 Laxenburg $[+43$ (2236) $715210 / 713$ 13]

ILL - Institut Laue-Langevin, J. Charvolin (Dir.), BP 156X, F-38042 Grenoble Cédex [+33 () 76207111 / 762039 06]

IMEKO - Int. Measurement Confederation, T. Kemény (Sec.-Gen.) POB 457, H-1317 Budapest 5 [+36 (1) 1531562 / 15612 15]

Int. Assocn. of Mathematical Physics, D. lagolnitzer (Sec.), DSM, CEA-Saclay, F-91191 Gif-sur-Yvette [+33 (1) 69087385 / 690881 20]

Int. Optometric \& Optical League, D.A. Leason (Exec. Sec.),

10 Knaresborough Place, SW5 OTG London, UK [+44 (71) $3704765 / 3731143]$

ISGRG - Int. Soc. on General Relativity \& Gravitation, A. Held (Sec.), Secretariat ISGRG, Inst. of Theoretical Physics, Silderstr. 5 , $\mathrm{CH}-3012$ Bern [+41 (31) — / 6544 05]

ISO - Int. Standards Org., L.D. Eicher (Sec.-Gen.), CP 56 , CH-1211 Geneva 20 [+41 (22) $7341240 / 73334$ 30]

ISTCP - Int. Soc. for Theoretical Chemical Physics, J. Ladik (Pres.), Inst. für Physikalische und Theo. Chemie, Univ. Erlangen-Nürnberg, W-8520 Erlangen $[+49$ (9131) 857766 / 8583 07]

IUCr - Int. Union of Crystallography, J.N. King (Exec. Sec.), 5 Abbey Sq., Chester, CH1 2HU Chester, UK [+44 (244) 4345431 / 3448 43]

IUPAP - Int. Union of Pure \& Applied Physics, J.S. Nilsson (Sec.-Gen.), Vasaparken, Univ. of Göteborg, S-411 24 Göteborg [+46 (31) $631883 / 634660]$

IUTAM - Int. Union of Theo. \& Applied Mechanics, W. Schiehlen (Sec.-Gen.), University of Stuttgart, Pfaffenwaldring 9, W-7000 Stuttgart $80[+49(711)-/ 6853500]$

IUVSTA - Int. Union for Vacuum Science, Techniques \& Applications, J.S. Colligan (Gen.-Sec.), EE Dept., Salford Univ., Salford M5 4WT, UK $[+44$ (61) $7455247 /-]$

JET Joint Undertaking, P.-H. Rebut (Dir.), Abingdon OX14 3EA, UK [+44 (235) $528822 / 4637$ 06]

JINR - Joint Institute for Nuclear Research, V. Kadesheveski (Dir.), Head Post Office, P.O. Box 79, CIS-101 000 Dubna/Moscow [+7 (095) $9262251 / 2002283]$

JPS - The Physical Soc. of Japan, D.Y. Takada (Sec.-Gen.), Kikai-Shinko Bldg, 3-5-8 Shiba-koen, Minato-ku, Tokyo 105, Japan [+81 (3) $34342671 / 343209$ 97]

JRC - Joint Research Centre, Directorate-General, Comm. of the EC, 200, rue de la Loi, B-1049 Brussels [+32 (2) 2358527 / 2350146 ]

JSAP - The Japan Soc. of Applied Physics, J. Tsujiuchi (Pres.), Kunimatsu Bldg, 1-2-6 Kudan-kita, Chiyoda-ku, Tokyo, Japan 102 $[+81$ (3) $2381041 / 2216245]$

NATO - Scientific Affairs Div., J.-M. Cadiou (Ass. Sec.-Gen. for Scientific \& Environ. Affairs), B-1110 Brussels [+32 (2) $7284111 / 72842$ 32]

NuPECC - Nuclear Physics European Collaboration Committee, C. Détraz (Chair.), LPC/ISMa, blvd du Maréchal Juin, F-14032 Caen Cédex [+33 () 31452508 / 314525 49]

OECD - Org. for Economic Co-operation \& Development, N. Tanaka (Dir., Sci., Tech. \& Industry), H. Currien (Chair., Committee on Scientific \& Technical Policy): 2, rue André Pascal, F-75775 Paris Cédex 16 [+33 (1) - / 45249399$]$

Physics Olympiad, V. Gorkowski (Chair., Int. Organising Committee), Inst. of Physics, Polish Acadamy of Sciences, al. Loitników 32/46, PL-02668 Warsaw $[+48$ (22) $435212 / 4309$ 26]

PRI - Plastics \& Rubber Inst., 11 Hobart Place, UK-London SW1W OHL $[+41$ (71) $2459555 / 8231379]$
PTB - Physikalisch-Technische Bundesanstalt, D. Kind (Pres.)

Postfach 3345, W-3300 Braunschweig

[+49 (531) $5921000 / 5924006]$

SISSA - Scuola Internazionale Superiore de Studi Avanzati, D. Amati (Dir.), Via Beirut, 4, 1-34014 Trieste [+39 (40) 3787414 / 37875 28]

UNESCO - United Nations Educational, Scientific \& Cultural Organization,

F. Mayor Zaragoza (Dir.-Gen.), S.W. Raither (Physics Prog., Div. of Basic Sciences), 7, place de Fontenoy, BP 3.07, F-75700 Paris

[+33 (1) $45681000 /$ - ]

URSI - Int. Union of Radio Science, J. Van Bladel (Sec.-Gen.), Obs. Royal de Belgique, 3, ave Circulaire, B-1180 Brussels [+32 (2) 3741308 / - ]

World Laboratory, A. Zichichi (Pres.), Int. Center for Science \& Culture,

6, pl. de la Riponne, CH-1005 Lausanne [+41 (21) 201631 / 201626 ]

\section{EPS-APS Presidential Letter}

A letter from the Presidents of the European Physical Society (EPS) and The American Physical Society (APS) which will be sent to institutions and to government agencies.

On May 25-27 May 1992, the East-West Coordinating Committee of the EPS, the Chairs of the Committee on International Scientific Affairs, the Forum on International Physics, and the Panel on Public Affairs of the APS met in Budapest. The President, President-Elect and Executive-Secretary of the APS, the President and Vice-President of EPS, and members of the EPS Secretariat also attended the meeting. Its purpose was discussion of joint actions and coordination of activities to relieve the corrosive conditions threatening basic science in east-central Europe (Albania, Bulgaria, Croatia, Czechoslovakia, Hungary, Poland, and Romania were represented at the meeting) and the countries which make up the former Soviet Union.

As a result of the meeting, M. Jacob, President of EPS, and E.M. Henley, President of APS, wish to stress the following proposed joint initiatives.

1. The two societies will make efforts to seek improved communications to, from, and in the region through the development of both human and modern electronic networks.

2. We shall coordinate efforts to provide journal subscriptions and missing research publications to the libraries of the major research institutions.

3. We shall provide assistance, to the extent possible, in the formation of new, and in the strengthening of established, collaborations between eastern and western groups. We are convinced that the "bottom up" approach is one of the most efficient ways to help our colleagues in central-east Europe and in the former Soviet Union.

4. Lists of peer reviewers will be drawn up and made available upon specific requests from appropriate organizations, for the evaluation of institutions, programmes and scientific proposals. Both central-east European as well as former Soviet Union institutions and governmental funding agencies will be apprised that the EPS and APS favour external reviews and can assist through providing a list of suitable reviewers.

5. We shall announce our active support and encouragement for the retention of appropriate existing, and the development of new, centres of excellence in the region.

6. We shall seek ways to enhance the coordination of our activities in central-east Europe and in the republics of the former Soviet Union. We shall continue to exchange information about current conditions and activities with a view to supporting each other's activities.

Some of the above steps are in the form of joint presidential statements communicated to colleagues, institutions, governments, international agencies, and non-governmental organizations. In addition, we shall seek to develop joint society declarations of principles, programme commitments and calls for action.

The health and prosperity of all nations are dependent upon the vitality of international scientific enterprise. We stand united, as physicists, to search for solutions to the current crises and we declare our resolve to join together to preserve the culture of international science.

Maurice Jacob

European Physical Society
Ernest Henley

The American Physical Society 